\title{
Fuzzy Forecasting of the Cash Flow Statement Based on Accounting Data
}

Kaspina R.G.

\section{Molotov L.A.}

Kazan Federal University, Institute of Management, Economics and Finance, Kazan, 420008, Russia

\section{Doi:10.5901/mjss.2014.v5n24p237}

\section{Abstract}

This article is devoted to the practical aspects of the cash flow statement forecast. The proposed formation method is based on the fuzzy logics and the procedure of expert evaluations. As the result of premade theoretical analysis of the financial statements fuzzy forecast, a computer program has been developed to support the formation of the forecasted cash flow statement. The article describes the software's working algorithm and presents its main windows.

Keywords: Cash flow statement forecasting, fuzzy sets, expert evaluations, computer software.

\section{Introduction}

Universally, the term "cash flow management" refers to a guarantee of independence and a state of stability and efficiency within a company - the key to financial success. Therefore, accounting and cash flow analysis are some of the top priorities of the firm.

The forecasted cash flow statement is highly useful. Most notably, we can employ its use in the budgeting process. Budgeting, refers to the tactical (both short-term and medium-term) business actions planning $[1,2]$.

Secondly, another obvious utility of the forecast report may be clearly evident upon examination of investment designs. As a result, the prediction of cash flow from the implementation of a specific project can be deduced and a calculation of its efficiency can be thus acquired [4].

Additionally, another useful aspect that the cash flow statement may provide for interested users would lie in the prospect of financial structure evaluation (including stability, liquidity and solvency) of the enterprise, providing feedback about the rhythm of the operating process, the rate of funds turnover, etc. [4].

As a result, the upper management of the company will always be able to dictate the volume and the timing of the cash flows in order to adapt to the constantly changing circumstances and conditions of the financial world. Use of the cash flow statement also provides companies with an upper hand in capitalizing on future prospects and possibilities as they arise.

It should be also noted, that there is an increasing tendency to include superfluous amounts of forecasted information into formal financial statements [5]. Pure financial indicators related to profit generation alone, cannot always provide the investors and financial analysts with a truly reliable information base for predicting the long term value of an organization into posterity. Therefore, the value and credibility of financial statements is now determined more by its predictive components and not as much by the previously achieved results during past periods [6].

\section{Method}

The accounting information is the basis for the formation of a forecasted report, which determines the management decisions (Table 1). 
Table 1. Transformation of accounting information into a forecast

\begin{tabular}{|c|c|l|}
\hline Level & Stage & Description \\
\hline \multirow{2}{*}{ Operational } & $\begin{array}{c}\text { Business } \\
\text { event }\end{array}$ & \multirow{2}{*}{ Gathering and simple summation business events data } \\
\cline { 2 - 3 } & Data & \\
\hline $\begin{array}{c}\text { Operational }-> \\
\text { Strategic }\end{array}$ & Information & $\begin{array}{l}\text { The transformation of this data into accounting and analytical information which then goes } \\
\text { into the hands of trained professional for expert evaluation }\end{array}$ \\
\hline \multirow{2}{*}{ Strategic } & Forecast & $\begin{array}{l}\text { The received information is combined with previously accumulated statistics and past } \\
\text { statements which are thus evaluated and followed to transform this accumulation of data into } \\
\text { a form of forecast report }\end{array}$ \\
\cline { 2 - 3 } & Decision & At the final stage, this form is then used for management tasks \\
\hline
\end{tabular}

Now let us consider the existing methods (approaches) of financial and economic forecasting. Conventionally, they can be divided into two major groups: factual (formal) and expert (intuitive). Factual (formal) methods are based on actual available information with regard to a prediction. The expert (intuitive) methods employ the opinions of specialists and experts and are used when it is impossible to formalize the studied processes, or in case of varying degrees of uncertainty within the data. However, as a rule, different experts have different opinions about evaluating an index and often find it difficult to give exact estimates. The nature of estimation is one that relies on subjective perception and thus is difficult to be defined in terms of absolutes. For situations such as these we suggest using the method of fuzzy-sets, which works with the indicators in the form of fuzzy numbers.

Let us give the theoretical description of the algorithm for constructing the membership function (MF) of fuzzy numbers represented in Formula 1 [7]. Using the function of the form

$$
\mu_{K}(u)=e^{-\alpha(K-u)^{2}}, u \in U,
$$

where: $U$ - universal set (in the general case, the set of real numbers), then we build numbers' MF approximately equal to some number $\mathrm{K}$, where the parameter (Formula 2) depends on the fuzzy degree. Value is determined from the expression

$$
\alpha=\frac{-4 \ln 0,5}{(\beta(K))^{2}},
$$

where: - the distance between the transition points where the MF is set to 0.5 (we denote these points by $a$ and $b$, assuming that ).

In order to ensure full and well-timed forecasting of financial indicators we suggest using computer programs to automate this process $[8,9,10,11]$.

Therefore, after the analysis of the theoretical model of decision-making based on fuzzy initial information, we have implemented it in the form of a computer program [12, 13, 14, 15].

\section{Result}

We developed an algorithm for a special computer program to support the process of fuzzy forecasting of financial and economic indicators based on expert evaluations method. The software has been written in Java language in NetBeans 7.3 environment.

The program works in three modes: administrator, system analyst and expert [16]. The administrator is responsible for the initial operations of the program, such as making up usernames / passwords for the rest of the project's members. System Analyst regulates the work of experts, checking the iteration process, but does not have access to the passwords of experts and therefore cannot arbitrarily change their decision [17]. Experts work independently from each other and cannot see the projections of other experts [18].

Now let us describe the steps of working with the program. In the start window the user is prompted to create a new project or to select a project from the saved ones (Figure 2). 


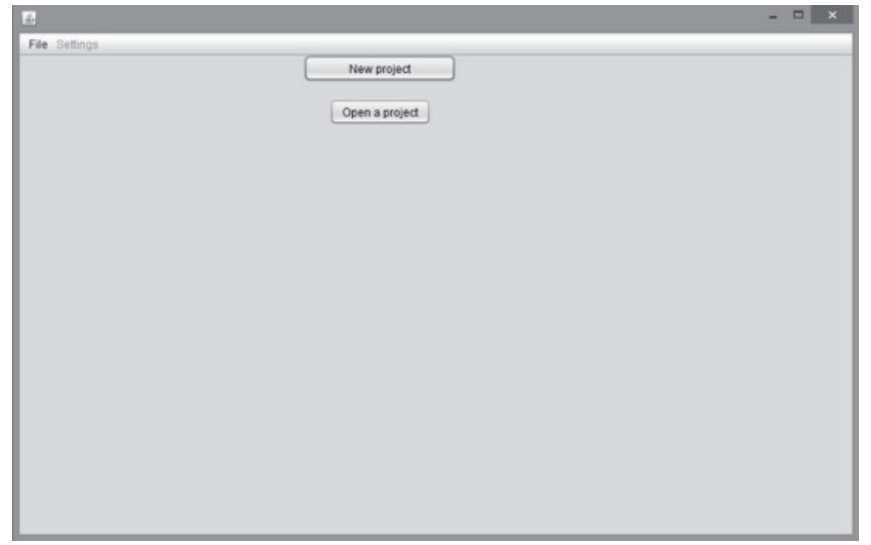

Fig. 2 Start window

New projects are started by the administrator who assigns the project ID, name / login / password for system analysts and experts and sets the name and purpose of the project (Figure 3) [19].

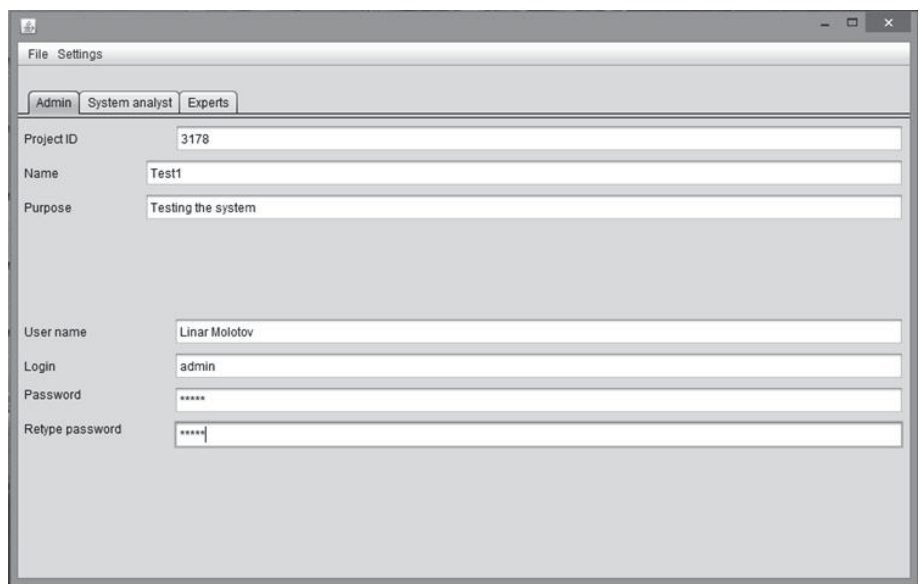

Fig. 3 Editing a new project

Then each expert writes their initial intervals (Figure 4); systems analyst checks and analyzes them; decides whom to include in the main experts group and whom to ask to change the interval values, or even exclude [20, 21].

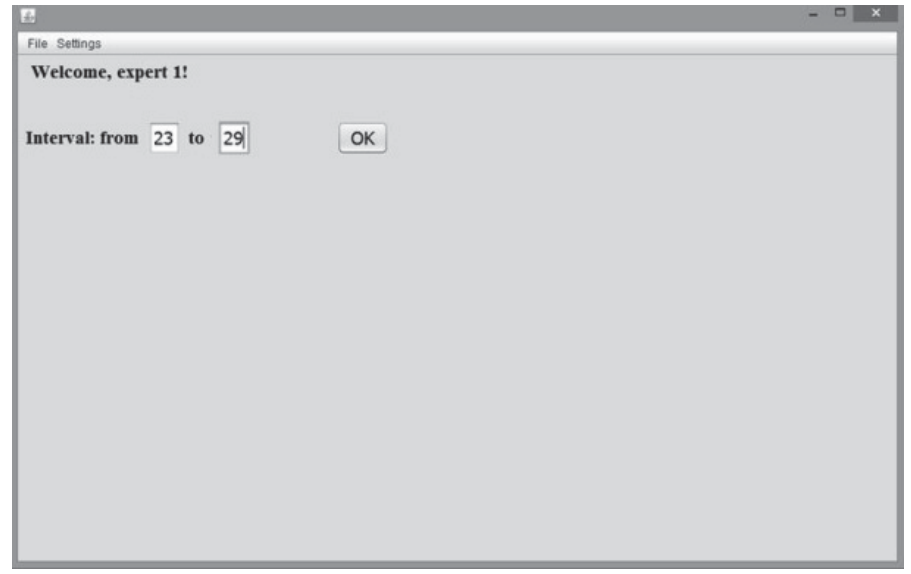

Fig. 4 Filling the interval values by an expert 
In the next step, each expert independently fills a matrix of priorities (Figure 5), after which the system analyst upon reexamining the data, combines matrices and carries out the first iteration (Figure 6).

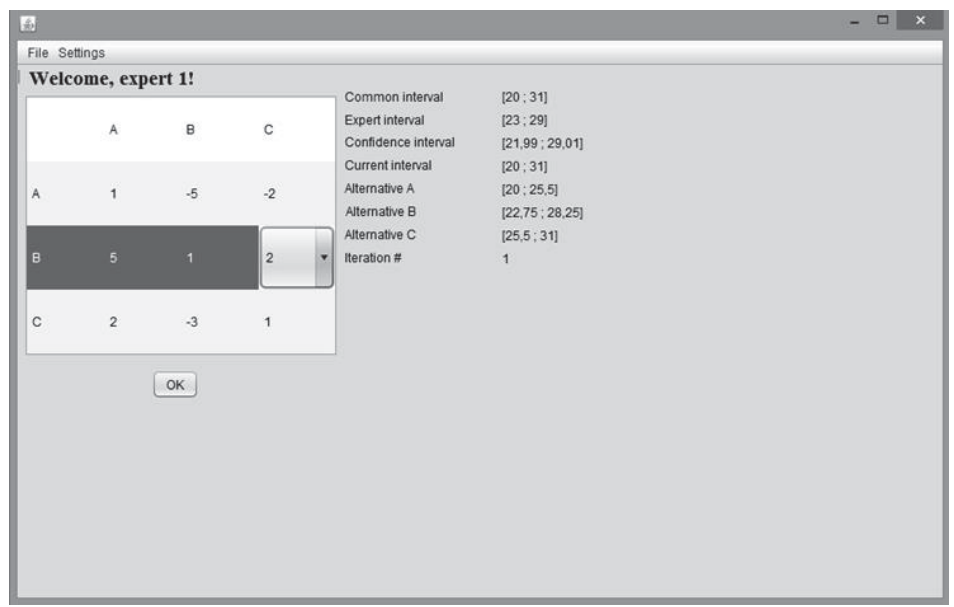

Fig. 5 Filling matrix of priorities by an expert

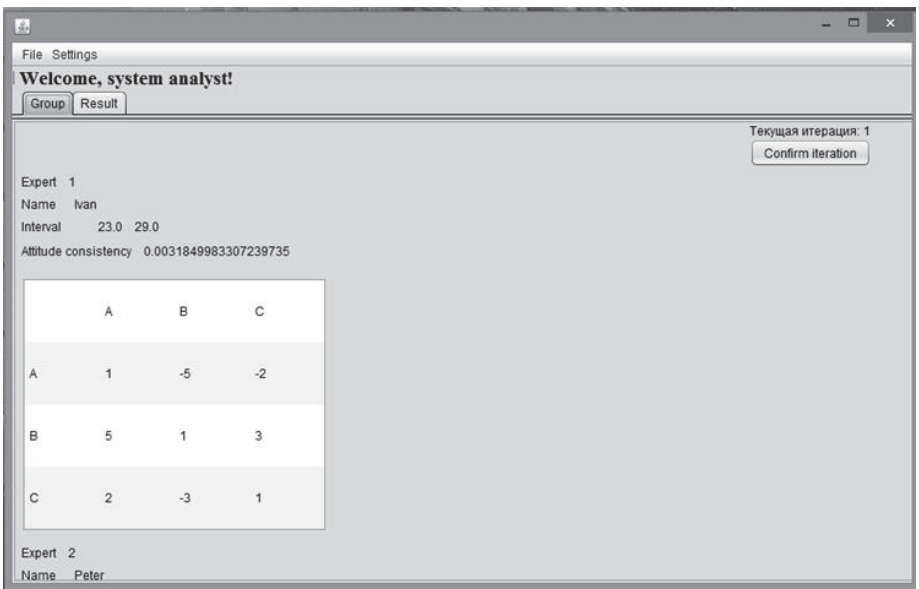

Fig. 6 Checking data by systems analyst. Conducting iteration

Then, following the fuzzy forecasting algorithm, the program checks whether or not the predicted interval fits in the confidence interval. If the condition is satisfied, then we can define the fuzzy forecast (Figure 7), otherwise, experts and systems analysts continue the iteration process.

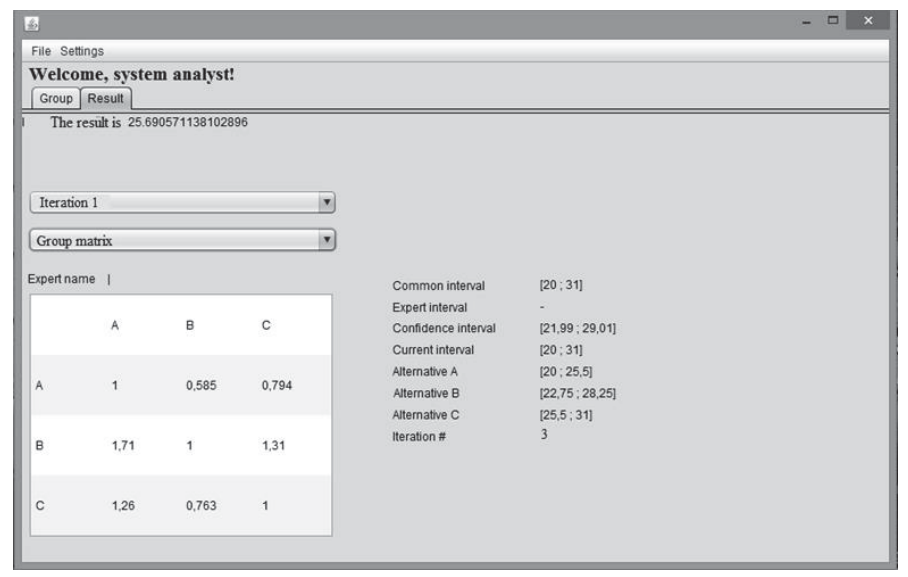

Fig. 7 Result window 
The program is built according to the MVC pattern - the object-oriented method for the separation of presentation logic, business logic and data model.

The main components are the Model, View and Controller. The Model is the aggregate data model domain, implemented in the application, in this case, for example, the model of the interval (Interval) or users model (Person). A major role is played by the model matrix (Matrix), which holds all the basic computation.

View - is the component responsible for displaying models and realizations of the user interface (Graphics User Interface). The project uses a standard package of Swing, as this library provides more flexible interface components than its predecessor, AWT.

The third component is the Controller. It focuses all the working logic of the application, binding Model and View together. The application includes many controllers. The most significant of which are XMLCreater, XMLParser, MatrixUnifier, IntervalUnifier. The first two process data stored in xml while the others deal with the main calculations.

The program uses both standard library of JDK and complement-enforcement, particularly the XOM library, which works and saves projects in the files of type «.xml» and Commons-Math for formatting matrixes.

\section{Conclusion}

Building an effective business system is impossible without proper and timely formatted forecast statements. The proposed tool (the computer software) provides the necessary mechanism for this process.

It should also be noted that the described method of fuzzy forecasting and the associated computer program presented in this article are sufficiently universal and will increase the reliability of the decision making process in a wide range of financial and economic systems.

\section{References}

Safiullin L.N., Ismagilova G.N., Safiullin N.Z., Bagautdinova N.G. The development of welfare theory in conditions of changes in the quality of goods and services (2012) World Applied Sciences Journal 18 (Special Issue of Eco-nomics), pp. 144-149.

Kaspina, R.G. and L.A. Plotnikova, 2014. Accounting of external economic activity of Russian companies: Experience and difficulties. Life Science Journal, 11 (11): 108-111.

Kaspina, R.G., L. S. Khapugina and E. A. Zakirov, 2014. Employment of activity-based costing in the process of company business model generation. Life Science Journal, 11 (8): 356-359.

Markaryan, S.E., T. A. Snetkova and D. V. Khairullina, 2014. Administrative aspects of accounting organization. Russian experience and problems. Life Science Journal, 11(8): 107-111.

Needles Jr., B.E., A. Shigaev, M. Powers and M. L. Frigo, 2014. Operating characteristics of high performance companies: Strategic direction for management. Studies in Managerial and Financial Accounting, 28: 25-51.

Needles Jr., B.E., A. Shigaev, M. Powers and M. L. Frigo, 2010. Strategy and integrated financial ratio performance measures: A Iongitudinal multi-country study of high performance companies. Studies in Managerial and Financial Accounting, 20: 211-252.

Zadeh L.A., 1978. Fuzzy sets as a basis for a theory of possibility. Fuzzy Sets and Systems, 1 (1): 3-28.

Garrison R.H. and E.W. Noreen, 1994. Managerial Accounting: Concepts for Planning, Control, Decision Making, 7th ed., IRWIN: 190.

Shneidman, L.Z., 2012. Review of Consolidated Reporting Structure in Russia Accounting, 11: 6-9.

Needles B.E., M. Powers, S. K. Mill and H. R. Anderson, 1999. Managerial Accounting, Boston, N.-Y.: Houghton Mifflin Company: 603.

Cooper, R. and R. Kaplan, 1992. Activity-based systems: Measuring the costs of resource usage. Accounting Horizons, September: 14.

Babad, Y. and B. Balachandran, 1993. Cost Driver Optimization in Activity-Based Costing. The Accounting Review, 68 (3): 563-575.

Hambrick, D. C. and J. W. Friedrickson, 2001. Are you sure you have a strategy? The Academy of Management Executive, 4 (November): 48.

Chesbrough, H., 2008. Open Business Models: IP-Management; Translation into Russian by V.N. Yegorova. Moscow: Pokoleniye, pp: 167.

Bossidy, L. and R. Charan, 2001. Confronting Reality. Doing What Matters to Get Things Right; Translation into Russian. Moscow: Williams P.H., pp: 288.

Porter, M. E. 1985. Competitive Advantage: Creating and Sustaining Superior Performance. New York: Free Press, pp: 592.

Brugemann, W., P. Everaert, S. R. Steven and Y. Levant, 2005. Modeling Logistic Costs using TDABC: A Case in a Distribution Company. University Ghent, Faculty of Economics and Business Administration. Date Views 13.08.2013 www.ideas.repec.org /p/rug/rugwps/05-332.html.

Kaplan, R. S. and S. R. Anderson, 2004. Time-Driven Activity-Based Costing. Harvard Business Review, November: 45.

Armstrong, P., 2002. The costs of activity-based management. Accounting, Organizations and Society, 27: 99-120.

Johnson, M., C. Christensen and H. Kagermann, 2009. Reinventing Your Business Model. Harvard Business Review. March: 63-72.

O'Guin, M. and A. S. Rebischke, 1996. Customer-Driven Costs Using Activity Based Costing. Handbook of Cost Managment. NY, Waren, Gorham \& Lamont: B5-1-B5-29. 